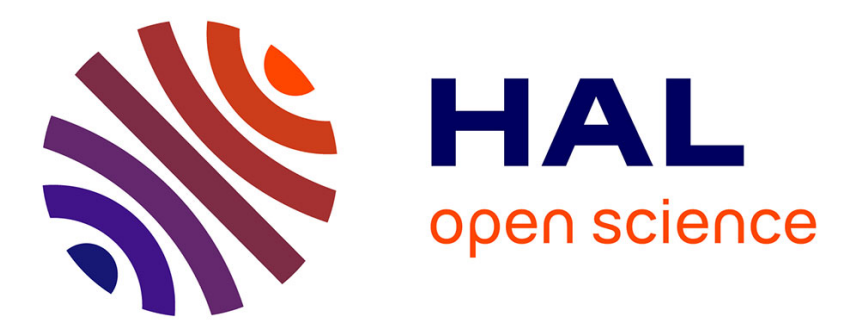

\title{
Self-compression and Raman soliton generation in a photonic crystal fiber of $100-f$ s pulses produced by a diode-pumped Yb-doped oscillator
}

Frédéric Druon, Nicolas Sanner, Gaëlle Lucas-Leclin, Patrick Georges, Kim M. Hansen, Anders Petersson

\section{To cite this version:}

Frédéric Druon, Nicolas Sanner, Gaëlle Lucas-Leclin, Patrick Georges, Kim M. Hansen, et al.. Self-compression and Raman soliton generation in a photonic crystal fiber of 100-fs pulses produced by a diode-pumped Yb-doped oscillator. Applied optics, 2003, 42 (33), pp.6768-6770. 10.1364/AO.42.006768 . hal-00761298

\section{HAL Id: hal-00761298 \\ https://hal-iogs.archives-ouvertes.fr/hal-00761298}

Submitted on 5 Dec 2012

HAL is a multi-disciplinary open access archive for the deposit and dissemination of scientific research documents, whether they are published or not. The documents may come from teaching and research institutions in France or abroad, or from public or private research centers.
L'archive ouverte pluridisciplinaire HAL, est destinée au dépôt et à la diffusion de documents scientifiques de niveau recherche, publiés ou non, émanant des établissements d'enseignement et de recherche français ou étrangers, des laboratoires publics ou privés. 


\title{
Self-compression and Raman soliton generation in a photonic crystal fiber of 100 -fs pulses produced by a diode-pumped Yb-doped oscillator
}

\author{
Frédéric Druon, Nicolas Sanner, Gaëlle Lucas-Leclin, Patrick Georges, \\ Kim P. Hansen, and Anders Petersson
}

\begin{abstract}
We present the use of a photonic crystal fiber to straightforwardly compress ultrashort pulses from a diode-pumped ytterbium laser emitting around $1 \mu \mathrm{m}$. 75-fs pulse generation and a large $1-1.3-\mu \mathrm{m}$ tunability for sub-100-fs pulses is reported. (C) 2003 Optical Society of America

OCIS codes: $320.7140,320.5520,060.5530$.
\end{abstract}

Photonic crystal fibers (PCFs), also known as holey or microstructured fibers, have sparked a great deal of interest owing to their novel dispersion properties and the opportunity for propagation within a tightly confined fundamental spatial mode. PCF technology has allowed a breakthrough in the domain of nonlinear processes involving ultra-short pulsed lasers emitting in the near-infrared range. In fact, this new generation of fibers demonstrates zero dispersion and anomalous group velocity dispersion (GVD) for submicrometer wavelengths, ${ }^{1}$ e. g., enabling propagation of femtosecond solitons without time stretching and the subsequent drop of pulsepeak intensity. The longer effective nonlinear interaction length of these fibers has led to very innovating results at 800 (Refs. 2-5) and $1 \mu \mathrm{m}$ (Refs. $6-8$ ). In this paper, we present the use of a holey fiber to straightforwardly compress pulses of a femtosecond oscillator emitting around $1 \mu \mathrm{m}$. Moreover, we demonstrate the most compact and simplest, to our knowledge, largely tunable (in the range of 1-1.3 $\mu \mathrm{m})$ sub-100-fs laser source.

The laser source is a simple diode-pumped pulsed

F. Druon (frederic.druon@iota.u-psud.fr), N. Sanner, G. LucasLeclin, and P. Georges are with the Laboratoire Charles Fabry de I'Institut d'Optique, Unité Mixte de Recherche 8051 du Centre National de la Recherche Scientifique, Centre Universitaire d'Orsay, Bâtiment 503, 91403 Orsay, France. K. P. Hansen and A. Petersson are with Crystal Fibre A/S, Blokken 84, DK-3460 Birkerød, Denmark.

Received 20 March 2003; revised manuscript received 15 July 2003.

0003-6935/03/336768-03\$15.00/0

(C) 2003 Optical Society of America oscillator based on an Yb:SYS crystal. ${ }^{9}$ Figure 1 shows the experimental setup. This oscillator produces $110-\mathrm{fs}$ pulses at a repetition rate of $108 \mathrm{MHz}$ and with an average power of $110 \mathrm{~mW}$, which corresponds to a peak power per pulse $\left(P_{p}\right)$ of $9 \mathrm{~kW}$. The central wavelength of the pulses is $1068 \mathrm{~nm}$, and the bandwidth is $14 \mathrm{~nm}$, equivalent to a time-bandwidth product (TBP) of 0.4. The TEM OO $_{00}$ output beam of this oscillator is injected into a PCF (Fig. 1). The incident polarization and the coupled power in the fiber are controlled with two mirrors and a half-wave plate. In these conditions, we can continuously adjust the intensity in the fiber without modifying the performances of the oscillator; one can notice that the beam always remains spatially $\mathrm{TEM}_{00}$ at the output of the PCF, as shown in Fig. 1. To inject properly the oscillator beam in the PCF and to control precisely the coupled power, we pay attention to having a precise and stable alignment for the injection in the fiber. In these conditions and thanks to the good stability of the Yb:SYS oscillator, no problem of power fluctuation has been observed at the output of the fiber.

The experiment is performed with a 95-cm-long photonic crystal fiber from Crystal Fibre A/S (Birkerød, Denmark). This fiber (represented in Fig. 1) has a core diameter $\left(l_{c}\right)$ of $2.6 \pm 0.2 \mu \mathrm{m}$, a structure pitch of $2.0 \pm 0.3 \mu \mathrm{m}$, and a pitch-to-hole ratio of 0.35 . To couple the laser beam in the PCF, we use a 4-mmfocal-length microscope objective. The maximum of the coupling efficiency is then $\sim 30 \%$. This fiber has been chosen for its interesting properties of dispersion. The fiber exhibits zero dispersion at $950 \mathrm{~nm}$ and a negative GVD of $\sim 20 \mathrm{ps} / \mathrm{nm} / \mathrm{km}$ at $1060 \mathrm{~nm}$, consequently allowing soliton propagation and possi- 


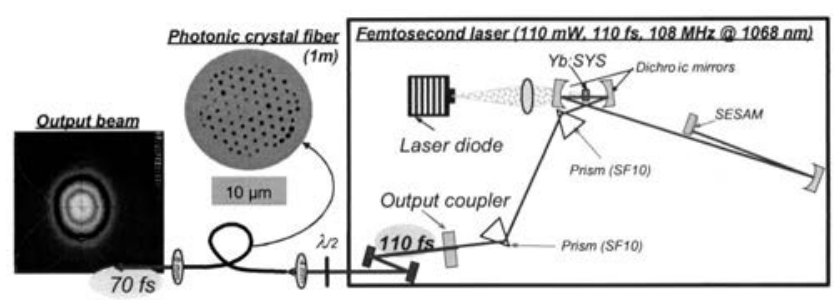

Fig. 1. Experimental setup with the Yb:SYS oscillator and the PCF, the structure of which is illustrated in inset (a). The output beam of the system is shown in inset (b).

ble pulse compression for femtosecond lasers based on ytterbium-doped crystals.

At low coupled power corresponding to an average power of $3 \mathrm{~mW}$ at the output of the PCF, pulse compression has been obtained directly at the output of the fiber (without additional post-compression system). As shown in the autocorrelation traces presented in Fig. 2, pulses of $75 \mathrm{fs}$ (FWHM) have been produced corresponding to a compression factor of 1.5. The spectrum broadens from 14 to $18 \mathrm{~nm}$ thanks to the self-phase modulation (SPM). At the output of the PCF the TBP is then 0.35. At this low level of power, the spectrum generated by the SPM is efficiently recompressed by the negative GVD of the $\mathrm{PCF}$. The experimental results of self-compression can be substantiated by a simple model, taking into account only dispersion and SPM. ${ }^{10}$ Actually, considering the following set of values $D=26 \mathrm{ps} / \mathrm{nm} /$ $\mathrm{km}, P_{p}=250 \mathrm{~W}, l_{c}=2.7 \mu \mathrm{m}$, and $n_{2}=2.710^{-20}$ $\mathrm{m}^{2} / \mathrm{W}^{p}\left(\mathrm{n}_{2}\right.$, the nonlinear index $)$, which corresponds to a initial soliton number ${ }^{10} N_{i}=1.3$, this model produces 74 fs (equivalent to a final soliton number $N_{f}=$ 1.07). In our conditions the pulse compression appears, since $2 \mathrm{~mW}$ of optical power coupled in the fiber. For $3 \mathrm{~mW}$, the experimental pulse compression factor reaches 1.47. This value is near the maximum compression factor that is achievable in our $\mathrm{PCF}$, although the length was not optimized in our experiment. Actually, our simulations predict that, for an initial soliton number of $N=1.3$, an optimal compression factor of 1.7 (corresponding to $N_{f} \approx 1$ ) should be reached for an fiber length of $35 \mathrm{~cm}$.

With higher powers coupled in the PCF, other nonlinear effects such as stimulated Raman scattering and soliton self-frequency shift begin to appear.

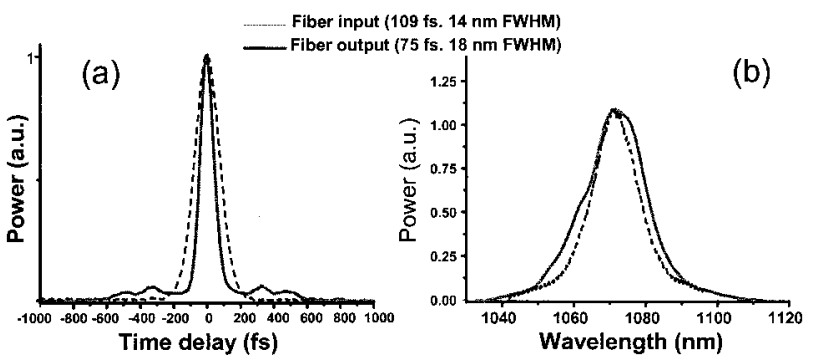

Fig. 2. Autocorrelations (a) and spectra (b) of the pulses before and after self-compress the PCF.

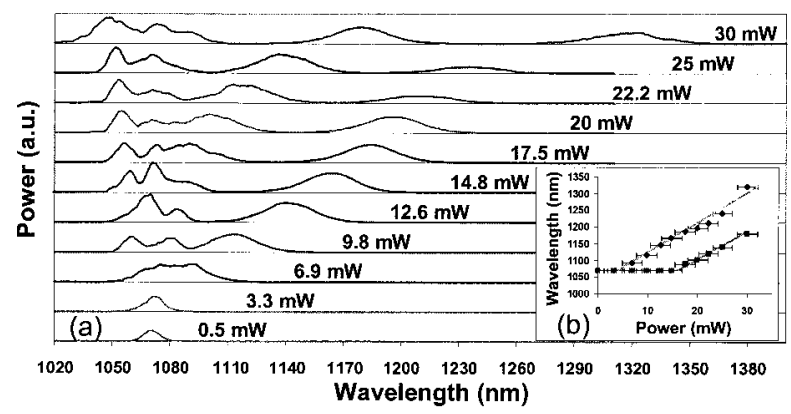

Fig. 3. Spectra at the output of the fiber (a) and Raman-soliton central wavelength as a function of coupled power (b).

Thus, with the increase of the peak intensity in the PCF, new Raman solitons are created and start to spectrally (Fig. 3) and temporally (Fig. 4) split up from the fundamental soliton. The role that this "soliton fission" process plays during pulse propagation in PCF has been discussed in detail in Refs. 11 and 12. In our experiments, a first Raman soliton begins to be clearly distinguishable for an average coupled power of $4 \mathrm{~mW}$ (injected soliton number $N_{i} \approx$ $1.5)$, and a second one appears for a power of $16 \mathrm{~mW}$ $\left(N_{i} \approx 3\right)$. The soliton self-frequency shift is continuous and linear versus the power coupled in the PCF [fig. 3(b)]. It is then possible to easily generate tunable solitons from 1 to $1.3 \mu \mathrm{m}$ with a tunability factor of $9 \mathrm{~nm} / \mathrm{mW}$. In the temporal domain, the delay between the two Raman solitons and the fundamental soliton also increases with the pulse energy in the fiber. This time delay reaches $2.59 \mathrm{ps}$ for the first soliton and 0.55 for the second one at the maximum coupled power. Moreover, Raman soliton selfcompression is also observed at the output of the PCF. Using the cross-correlation traces between the different solitons, we measure a compression factor between 1.5 and 2. For example, at the maximum coupled power $(P)=30 \mathrm{~mW})$, the durations for the three pulses are estimated to $73 \mathrm{fs}$ (at $1060 \mathrm{~nm}$ ), $64 \mathrm{fs}$ (at $1180 \mathrm{~nm}$ ), and $55 \mathrm{fs}$ (at $1317 \mathrm{~nm}$ ). For the fundamental soliton whose spectrum is highly altered by the SPM, the TBP increases to 0.9 . In contrast, as shown in Fig. 3, the Raman-soliton spectra are very smooth; the TBPs are relatively good: 0.35 and 0.37 for the first and the second soliton, respectively. The reduction of the pulse duration versus the wavelength can be easily understood, taking into

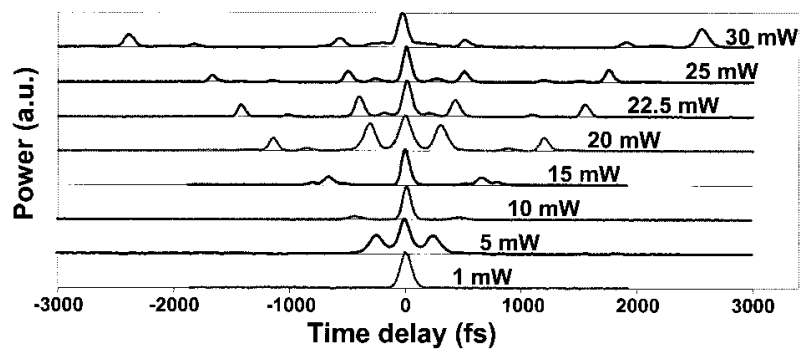

Fig. 4. Autocorrelation traces at the output of the PCF at eight different coupled powers. 
account that the soliton number is proportional to $\left(\langle P\rangle_{\tau} / \lambda^{3}\right)^{1 / 2}$, where $\tau$ is the pulse duration and $\lambda$ is the central wavelength. With this simple approach we conclude that the spectral shift of the Raman solitons implies an additional pulse compression. Considering a final soliton number $N_{f} \approx 1.5$ identical for the three solitons, we estimated that the global energy is then distributed between them as following: $6 \mathrm{~mW}$ for the fundamental, $10 \mathrm{~mW}$ for the second Raman, and $14 \mathrm{~mW}$ for the first Raman soliton, which is consistent with the Raman pulse split-up thresholds.

In conclusion, the use of PCF has allowed a direct compression of pulses from Yb-doped laser emitting in the $1-\mu \mathrm{m}$ region. This straightforward technique has resulted in a compression of $110 \mathrm{fs}$ pulses down to $75 \mathrm{fs}$. Moreover, thanks to a self-frequency shift of Raman solitons, it was possible to obtain a sub-100-fs source tunable from 1 to $1.3 \mu \mathrm{m}$. The soliton process permitted a compression of these Raman solitons, and $55 \mathrm{fs}$ at $1317 \mathrm{~nm}$ was then obtained. This new source, based on a diode-pumped oscillator and a simple process of frequency conversion, is therefore very interesting because of its remarkable simplicity.

\section{References}

1. M. J. Gander, R. McBride, J. D. C. Jones, D. Mogilevstev, T. A. Birks, J. C. Knight, and P. St. J. Russel, "Experimental measurement of group velocity dispersion in photonic crystal fiber," Electron Lett. 35, 63-64 (1999).

2. J. K. Ranka, R. S. Windeler, and A. J. Stentz, "Visible continuum generation in air-silica microstructure optical fibers with anomalous dispersion at $800 \mathrm{~nm}$," Opt. Lett. 25, 25-27 (2000).

3. B. R. Washburn, S. E. Ralph, P. A. Lacourt, J. M. Dudley, W. T. Rhodes, R. S. Windeler, and S. Coen, "Tunable near-infrared soliton in photonic crystal fiber," Electron. Lett. 37, 1510-1511 (2001).

4. I. G. Cormack, D. T. Reid, W. J. Wadsworth, J. C. Knight, P. St. J. Russel, "Observation of soliton self-frequency shift in photonic crystal fiber," Electron. Lett. 38, 167-168 (2002).

5. R. Holzwarth, M. Zimmermann, Th. Udem, T. W. Hänsch, P. Russbüldt, K. Gäbel, R. Poprawe, J. C. Knight, W. J. Wadsworth, and P. St. J. Russel, "White-light frequency comb generation with a diode-pumped Cr:LiSAF laser," Opt. Lett. 26, 1376-1378 (2001).

6. S. Coen, A. H. L. Chau, R. Leonhardt, J. D. Harvey, J. C. Knight, W. J. Wadsworth, and P. St. J. Russel, "White-light supercontinuum generation with 60 -ps pump pulses in a photonic crystal fiber," Opt. Lett. 26, 1356-1358 (2001).

7. J. H. V. Price, K. Furasawa, T. M. Monro, L. Lefort, and D. J. Richardson, "Tunable, femtosecond pulse source operation in the range 1.06-1.33 $\mu \mathrm{m}$ based on an $\mathrm{Yb}^{3+}$-doped holey fiber amplifier," J. Opt. Soc. Am. B 19, 1286-1294 (2002).

8. J. H. V. Price, W. Belardi, T. M. Monro, A. Malinowski, A. Piper, and D. J. Richardson, "Soliton transmission and supercontinuum generation in holey fiber, using a diode pumped ytterbium fiber source," Opt. Express 10, 382-387 (2002), http://www.opticsexpress.org.

9. F. Druon, S. Chénais, P. Raybaut, F. Balembois, P. Georges, R. Gaumé, P. H. Haumesser, B. Viana, D. Vivien, S. Dhellemmes, V. Ortiz, and C. Larat, "Apatite-structure crystal, $\mathrm{Yb}^{3+} \mathrm{SrY}_{4}\left(\mathrm{SiO}_{4}\right)_{3} \mathrm{O}$, for the development of diode-pumped femtosecond lasers," Opt. Lett. 27, 1914-1916 (2002).

10. G. P. Agrawal, Nonlinear Fiber Optics (Academic, San Diego, Calif., 1994).

11. A. V. Husakou and J. Herrmann, "Supercontinuum generation of higher-order solitons by fission in photonic crystal fiber," Phys. Rev. Lett. 87, 203901 (2001).

12. J. Dudley and S. Coen, "Coherence properties of supercontinuum spectra generated in photonic crystal and tapered optical fibers," Opt. Lett. 27, 1180-1182 (2002). 